\title{
Addition of Basal Insulin to Oral Antidiabetic Agents in Patients with Inadequately Controlled Type 2 Diabetes Leads to Improved HbA1c Levels: Metabolic Control, Frequency of Hypoglycemia, and Insulin Titration Analysis as Results of a Prospective Observational Study (BALI Study)
}

\author{
Jan Brož (D) · Denisa Janíčková Ždárská · Radka Štěpánová · Milan Kvapil
}

Received: January 7, 2019 / Published online: February 20, 2019

(c) The Author(s) 2019

\section{ABSTRACT}

Introduction: Despite the continuously growing number of therapeutic options for patients with type 2 diabetes mellitus (T2DM), a large percentage of these individuals fail to achieve their glycated hemoglobin (HbA1c) target. The aim of this study was to determine the change in metabolic control in insulin-naïve T2DM patients inadequately controlled with oral antidiabetic drugs (OADs) at 6 months after initiating basal insulin treatment as add-on to existing OADs.

Methods: This was a non-interventional prospective study conducted from June 2013 to December 2014 in 137 centers in the Czech Republic under routine clinical practice conditions. Adult patients whose diabetes was uncontrolled on their current OAD treatment (HbA1c $\geq 53 \mathrm{mmol} / \mathrm{mol}$; Diabetes Control and Complications Trial [DCCT]-HbA1c 7\%) and whose physician had decided to initiate

Enhanced Digital Features To view enhanced digital features for this article go to https://doi.org/10.6084/ m9.figshare.7679924.

J. Brož $(\bowtie) \cdot$ D. Janíčková Ždárská · M. Kvapil

Department of Internal Medicine, Second Faculty of

Medicine, Charles University, Prague, Czech

Republic

e-mail: zorb@seznam.cz

R. Štěpánová

Aprova s.r.o, Brno, Czech Republic treatment on a basal insulin regimen were documented over a 6-month period beginning from the time of initiation of basal insulin treatment.

Results: Overall, 1426 T2DM patients were included in the study, of whom 53\% were male. The mean age of the study population was 63.8 \pm 10.1 years, mean body mass index was $31.5 \pm$ $5.3 \mathrm{~kg} / \mathrm{m}^{2}$, and mean duration of diabetes was $10.2 \pm 5.3$ years. At the 6-month follow-up, the target HbA1c level of $53 \mathrm{mmol} / \mathrm{mol}$ (DCCT < $7 \%$ ) was achieved by $18 \%$ of patients. The mean HbA1c overall had decreased from $77.2 \pm 15.1$ $\mathrm{mmol} / \mathrm{mol}$ (DCCT $9.21 \pm 1.38 \%$ ) at baseline to $63.2 \pm 12.5 \mathrm{mmol} / \mathrm{mol}$ (DCCT $7.93 \pm 1.14 \%$ ) at the 6-month follow-up. This difference was significant at $p<0.001$. The largest mean reduction in HbA1c, i.e., $20.9 \mathrm{mmol} / \mathrm{mol}$ (DCCT $2.4 \%$ ) was observed in the group of patients with a baseline HbA1c of $\geq 9 \%$. The mean daily basal insulin dose at 6 months was $18.8 \pm 8.9$ units. Symptomatic hypoglycemia was reported in $12.3 \%$ of patients, of those only one patient $(0.1 \%)$ suffered from severe hypoglycemia.

Conclusion: The addition of basal insulin to the therapeutic regimen of insulin-naïve T2DM on OAD treatment resulted in an improved metabolic control of diabetes after 6 months of treatment. However, most patients did not achieve their HbA1c target, probably also due to inadequate titration of basal insulin.

Funding: Sanofi, Czech Republic. 
Keywords: Basal insulin; HbA1c; Hypoglycemia; Insulin initiation; Titration; Type 2 diabetes

\section{INTRODUCTION}

Despite the new types of oral antidiabetic medicinal products, many patients with type 2 diabetes mellitus (T2DM) do not achieve the recommended glycated hemoglobin HbA1c levels $(<53 \mathrm{mmol} / \mathrm{mol}$; Diabetes Control and Complications Trial [DCCT]-HbA1c 7\%) [1-3]. The risk of developing diabetes and the associated long-term micro- and macro-vascular complications is increased $[4,5]$ among such patients, and thus insulin therapy is often prescribed. Despite such clearly defined recommendations [6], however, some studies show that the initiation of insulin therapy occurs later than the level of metabolic control achieved would indicate [7-9]. In addition, even if insulin therapy is initiated, there is often insufficient titration of insulin doses and associated persistent suboptimal metabolic control of the disease. Contributing to this result are several factors, such as not respecting the recommended titration algorithms [10, 11], concerns about hypoglycemia or weight gain [12], and inadequate communication on this topic between the medical team and the patient [13].

The study reported here was conducted with the aim to describe the initiation of insulin therapy and associated titration habits and the achievement of HbA1c target values in patients with T2DM receiving routine medical care in the Czech Republic.

\section{METHODS}

\section{Study Design}

This is a non-interventional prospective study describing the practices associated with the initiation of insulin therapy in patients with T2DM whose condition was insufficiently controlled during treatment with oral antidiabetics drugs (OADs) under routine clinical practice conditions in the Czech Republic, for whom physicians decided to add basal insulin to the existing treatment regimen. Patients from 137 study centers across all regions of the Czech Republic and the Slovak Republic were eligible for entry, thereby ensuring the highest possible representativeness of the sample. Patients were enrolled into the study consecutively; the maximum number of patients per center was 15 and the minimum was five. All study procedures were carried out in accordance with the International Conference on Harmonization/ Good Clinical Practice. All participants provided written informed consent. The study was conducted from June 2013 to December 2014 in the Czech Republic.

\section{Study Population}

The inclusion criteria were a diagnosis of T2DM, age of $>18$ years, insulin naïvety, insufficient control of the diabetes on the current therapeutic regimen of OADs (HbA1c $\geq 53 \mathrm{mmol} / \mathrm{mol} ;$ DCCT $>7 \%$ ), and the decision of a diabetologist to initiate basal insulin treatment with insulin glargine 100 $\mathrm{U} / \mathrm{mL}$, insulin detemir, or insulin neutral protamine Hagedorn (NPH). A signed written informed consent form was also required.

The exclusion criteria were type 1 diabetes mellitus, pregnancy at inclusion, use of shortacting insulin for therapeutic reasons for a duration of $<12$ months, and treatment with glucagon-like peptide- 1 analogs.

All patients were provided with a glucometer and self-monitored their blood glucose level.

\section{Compliance with Ethics Guidelines}

This study was conducted in accordance with the Declaration of Helsinki (2004) and the International Conference on Harmonization (ICH) Guidelines for Good Clinical Practice (1996). The study design was approved by the country-specific regulatory authorities and ethical committees. All participants of the study provided signed informed consent. 


\section{Insulins Used in the Study}

None of the basal insulins available in the Czech Republic during the study period were excluded. The basal insulins included an intermediate-acting insulin (NPH) and long-acting insulin analogs (glargine $100 \mathrm{U} / \mathrm{ml}$, detemir).

\section{Outcomes}

The primary objective of the study was to determine the percentage of patients after 6 months of therapy with basal insulin with a HbA1c level of $<53 \mathrm{mmol} / \mathrm{mol}$ (DCCT $<7 \%$ ) in the overall participant population and in subgroups defined by baseline (pre-basal insulin) levels of $\mathrm{HbA} 1 \mathrm{c}$ as follows:

1. International Federation of Clinical Chemistry (IFFC)-HbA1c $<64 \mathrm{mmol} / \mathrm{mol}$ (DCCT $<8 \%)$

2. IFFC 64 to $<75 \mathrm{mmol} / \mathrm{mol}$ (DCCT 8 to $<9 \%)$

3. $\quad$ IFFC $\geq 75 \mathrm{mmol} / \mathrm{mol}($ DCCT $\geq 9 \%)$

The secondary objectives were to determine the proportion of patients with hypoglycemic events, mean change of HbA1c from baseline to the 6-month follow-up visit, mean change in fasting plasma glucose levels from baseline to the 6-month follow-up visit, mean change in body weight, and mean change in doses of basal insulin in the overall participant population and each of the three subgroups. Probable hypoglycemic events were registered by patients, and documented hypoglycemic events were obtained from glucometer records by a physician (as per American Diabetes Association definitions [14]).

\section{Data Collection}

Data were collected at the inclusion visit (Visit 1 [V1]) and at routine follow-up visits (Visits 2 and 3 [V2, V3]) at 3 and 6 months, respectively. The diabetologists participating in the study documented data on each patient on electronic case report form. During V1, insulin therapy was initiated, dosage was recommended, basic anamnestic data were recorded, and a physical examination and blood sampling were conducted to analyze basic patient parameters. The patient was instructed on the insulin therapies and possible dose titration according to the usual practice of the specific physician. Specific study recommendations were advised regarding insulin dose and the method of dose titration. During V2 and V3, the dose of insulin currently used by the patient was recorded and, if necessary, recommendations were made to adjust the dose. HabA1C values were determined and recorded during all study visits.

\section{Statistical Methods}

\section{Sample Size Determination}

As no similar data in the Czech Republic on primary analysis were available, the assumptions for sample size estimation were based on results published by Zhou et al. 2009 [15]. The assumed distribution of patients in the three subgroups of interest, namely, HbA1c $64 \mathrm{mmol} / \mathrm{mol}$ [DCCT <8\%], HbA1c $64-75 \mathrm{mmol} / \mathrm{mol}$ [DCCT 8 to $<9 \%$ ], and HbA1c $\geq 75 \mathrm{mmol} / \mathrm{mol}$ [DCCT 9\%]), was 25 , 35 , and $40 \%$, respectively; the assumed rates of patients with target values of $\mathrm{HbA1c}$ after 6 months of basal insulin therapy in these HbA1c subgroups were 75,55 and $35 \%$, respectively. The intention was to enrol a total of 1500 patients into the study. The expectation was that about $15 \%$ of these patients would not have any post-baseline value of HbA1c, leaving 1300 patients eligible for the analysis.

The analysis of 1300 patients would allow the percentage of patients to be determined with a precision of at least $6 \%$ and probability of $80 \%$. This would mean that at least a $3 \%$ halfwidth of $95 \%$ two-sided Wald confidence interval (CI) with continuity correction could be expected with a probability of at least $80 \%$. Further, under the assumptions of the expected $25 \%$ rate of patients with a baseline $\mathrm{HbA} 1 \mathrm{c}$ of $\leq 64 \mathrm{mmol} / \mathrm{mol}($ DCCT $\leq 8 \%)$ and expected $75 \%$ rate of patients who achieved target HbA1c levels in this subgroup, the number of enrolled patients would allow determination of the percentage of responder patients with a precision of at least $10 \%$ and probability of $80 \%$. This was 
the subgroup for which the precision would be the "worst."

\section{Data Analysis}

Statistical methods commonly used for analysis of epidemiological data were used. The twosided confidence intervals were calculated. If appropriate, the 95\% two-sided asymptotic Wald confidence interval with continuity correction was presented. All collected assessments were presented using descriptive statistics.

\section{RESULTS}

\section{Study Sample}

In total, 1488 patients with T2DM were enrolled into the study, with the final eligible population consisting of 1426 patients (53\% male). The number of patients with a baseline HbA1c level of $<64 \mathrm{mmol} / \mathrm{mol}$, of $\geq 64$ and $<$ $75 \mathrm{mmol} / \mathrm{mol}$, and of $\geq 75 \mathrm{mmol} / \mathrm{mol}$ was 242 (17.0\%), 485 (34.0\%), and 697 (48.9\%), respectively. An overview of patient characteristics for the total sample is shown in Table 1.

\section{Glycemic Control}

The proportion of patients with T2DM with an HbA1c value of $<53 \mathrm{mmol} / \mathrm{mol}$ (DCCT $<7 \%$ ) 6 months after the initiation of insulin therapy was $17.95 \%$ (95\% CI 15.93-19.98). Mean HbA1c for all patients together decreased from $77.2 \pm 15.1 \mathrm{mmol} / \mathrm{mol}$ (DCCT $9.21 \pm 1.38 \%$ ) at baseline to $63.2 \pm 12.5 \mathrm{mmol} / \mathrm{mol}$ (DCCT $7.93 \pm 1.14 \%$ ) at 6 months (significant difference at $p<0.001$ ), and the mean value of fasting glucose decreased from $11.3 \pm 3.27$ at baseline to $8.0 \pm 2.36 \mathrm{mmol} / \mathrm{l}$ at 6 months. The mean HbA1c and fasting glucose values obtained in all three study visits are shown in Table 2. The mean HbA1c values of individual patient groups collected during the course of the study, based on baseline values, are shown in Fig. 1. The largest reduction in HbA1c was
Table 1 Patient characteristics at the first (inclusion) visit

\begin{tabular}{ll}
\hline Patient characteristics & Values \\
\hline Type of diabetes & Type 2 DM \\
Total number of participants & 1426 \\
Males & $756(53.0 \%)$ \\
Females & $670(47.0 \%)$ \\
Categorization of patients according to baseline level of \\
HbAlc \\
$<64 \mathrm{mmol} / \mathrm{mol}$ \\
$\geq 64 \mathrm{mmol} / \mathrm{mol},<75 \mathrm{mmol} / \mathrm{mol}$ & $485(34.0 \%)$ \\
$\geq 75 \mathrm{mmol} / \mathrm{mol}$ & $697(48.9 \%)$
\end{tabular}

Demography and physical measurements

$\begin{array}{ll}\text { Age (years) } & 63.8 \pm 10.12 \\ \text { Weight }(\mathrm{kg}) & 91.7 \pm 17.33 \\ \text { BMI }\left(\mathrm{kg} / \mathrm{m}^{2}\right) & 31.5 \pm 5.33 \\ \text { Systolic BP }(\mathrm{mmHg}) & 137.9 \pm 14.44 \\ \text { Diastolic BP (mmHg) } & 80.5 \pm 8.98 \\ \text { Diabetic medical history } & \\ \text { Duration of DM (years) } & 10.2 \pm 6.41 \\ \text { Duration of OAD treatment (years) } & 8.6 \pm 5.43 \\ \text { Laboratory variables } & \\ \text { HbAlc (mmol/mol) } & 77.2 \pm 15.1 \\ \text { Fasting glucose (mmol/l) } & 11.3 \pm 3.27 \\ \text { Therapy (percentage of patients) } & \\ \text { Insulin glargine 100U/ml } & 91 \% \\ \text { Insulin detemir } & 5.4 \% \\ \text { Insulin NPH } & 3.4 \%\end{array}$

Values in table are presented as the number with the percentage in parenthesis or as the mean \pm standard deviation $(\mathrm{SD})$

$B M I$ Body mass index, $B P$ blood pressure, $D M$ diabetes mellitus, HbAlc glycated hemoglobin, $N P H$ neutral protamine Hagedorn, $O A D$ oral antidiabetic drug

$20.9 \mathrm{mmol} / \mathrm{mol}$ (DCCT 2.4\%) and was observed in the group of patients with a baseline HbA1c level of $\geq 75 \mathrm{mmol} / \mathrm{mol}$ (DCCT 9\%). 
Table 2 Mean glycated hemoglobin values, fasting glucose levels, body weight, and insulin doses

\begin{tabular}{|c|c|c|c|}
\hline Mean HbAlc and fasting glucose values & Visit $1^{a}$ & Visit $2^{a}$ & Visit $3^{a}$ \\
\hline \multicolumn{4}{|l|}{ HbAlc } \\
\hline $\mathrm{mmol} / \mathrm{mol}$ & $77.2 \pm 15.1$ & $66.1 \pm 15.4$ & $63.2 \pm 12.5$ \\
\hline DCCT (\%) & $9.21 \pm 1.38$ & $8.2 \pm 1.39$ & $7.93 \pm 1.14$ \\
\hline Mean fasting glucose $(\mathrm{mmol} / \mathrm{L})$ & $11.3 \pm 3.27$ & $8.4 \pm 2.46$ & $8.0 \pm 2.36$ \\
\hline Mean weight $(\mathrm{kg})$ & $91.7 \pm 17.33$ & $91.8 \pm 17.33$ & $92.1 \pm 17.35$ \\
\hline $\begin{array}{l}\text { Insulin dose recommended by physician at visit } \\
\text { (U/day, } U / \mathrm{kg} / \text { day })\end{array}$ & $\begin{array}{l}11.9 \pm 5.2 \\
0.13 \pm 0.06\end{array}$ & $18.1 \pm 8.4,0.20 \pm 0.09$ & $20.2 \pm 10.3 \cdot 0.22 \pm 0.11$ \\
\hline $\begin{array}{l}\text { Insulin dose titrated by patient during period } \\
\text { prior to visit }{ }^{c}(\mathrm{U} / \text { day, } U / \mathrm{kg} / \text { day })\end{array}$ & $\mathrm{N} / \mathrm{A}$ & $16.4 \pm 8.0,0.18 \pm 0.09$ & $18.8 \pm 8.9,0.21 \pm 0.10$ \\
\hline
\end{tabular}

DCCT Diabetes Control and Complications Trial, $N / A$ data not available

${ }^{a}$ V1, Inclusion visit at which time insulin therapy was initiated, and dosage was recommended; V2, V3, visits at 3 and 6 months, respectively, post initiation of insulin treatment, during which the dose of insulin currently used by the patient was recorded and, if necessary, recommendations were made to adjust the dose for the subsequent period

${ }^{b}$ Values are the average dose $( \pm S D)$ of basal insulin per day as recommended by a physician at the time of each visit for the subsequent period of study

${ }^{c}$ The dosage titrated by the patient him/herself during the period prior to the visit, based on insulin dosage recommended during V1. The dosage being administered by the patient was recorded at the 3-month visit (V2), and the physician again recommended dose adjustment for the subsequent period of study. This process was repeated during V3

\section{Average Insulin Doses and Weight Change During the Study}

The mean daily basal insulin dose at baseline (V1), 3 months post initiation of insulin therapy (V2), and 6 months post initiation of insulin therapy was $11.9 \pm 5.19,16.4 \pm 7.99$, and $18.8 \pm 8.9 \mathrm{U}$, respectively. The mean dose actually titrated by the patient and the mean basal insulin dose per day recommended by the physician for the duration of the study were (U/day): V1: $-/ 11.9 \pm 5.2 ; \quad$ V2: $16.4 \pm 8.0 /$ $18.1 \pm 8.4$; V3:18 .8 \pm 8.9/20.2 \pm 10.3 (Table 2; Fig. 2).

Mean insulin doses ( \pm SD; U/day) at Visits 1 , 2 , and 3 in groups of patients classified according to no change in HbA1c value at V2 ("no improvement") and as a change in HbA1c value at V2 ("any improvement") were: V1: $11.0 \pm$ $4.7 / 12.1 \pm 5.3 ;$ V2: $18.6 \pm 7.7 / 18.0 \pm 8.5 ; \mathrm{V} 3$ : $21.0 \pm 10.9 / 20.7 \pm 10.6$ (Table 3).

Mean weight increased form $91.7 \pm 17.33 \mathrm{~kg}$ at baseline (V1) to $91.8 \pm 17.33 \mathrm{~kg}$ after 3 months (V2) and to $92.1 \pm 17.35 \mathrm{~kg}$ after 6 months (V3) (Table 2).

\section{Incidence of Hypoglycemia During the Study}

Among the patients, 88 (6.3\%) experienced hypoglycemia during the period between V1 and V2, and $121(8.7 \%)$ patients experienced hypoglycemia during the period between V2 and V3. Hypoglycemic events were recorded in a smaller number of patients during the same periods ( $n=58$ and $n=88$, respectively). Only one patient $(0.1 \%)$ suffered from severe hypoglycemia (Table 4).

\section{DISCUSSION}

The aim of this observational study was to determine the manner in which basal insulin therapy was initiated among patients with T2DM whose HbA1c targets were not achieved on therapy with OADs. Our results show that the percentage of patients in our study who reached their target HbA1c levels after 6 months was significantly lower than that reported in large clinical trials [16-20]. It is quite evident 


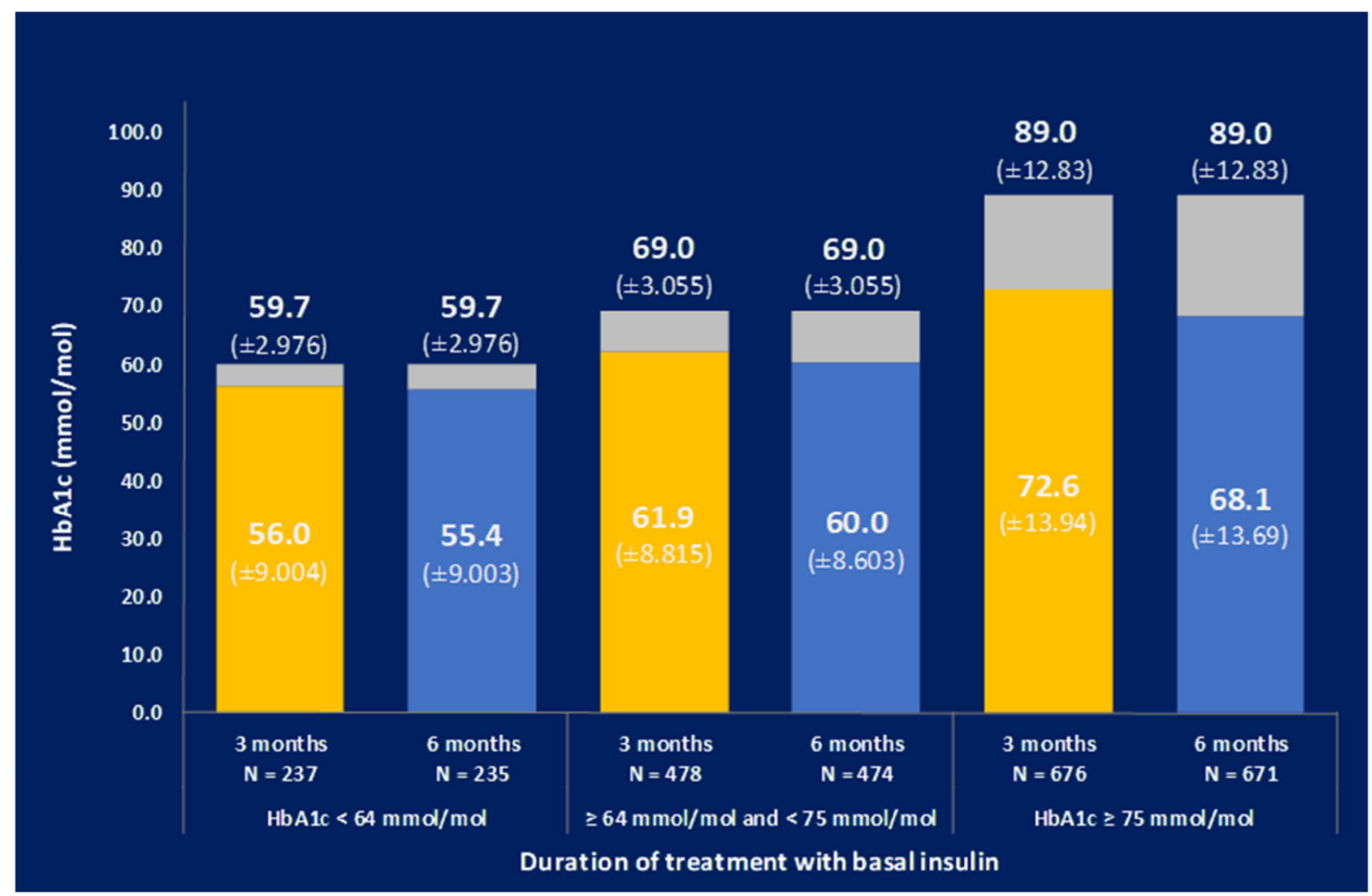

Fig. 1 Mean glycated hemoglobin $(H b A l c)$ values ( \pm standard deviation) at Visits 2 and 3 for the groups of patients according to baseline HbAlc value. Mean HbAlc value at Visit 1 (inclusion visit) is shown above the columns. The yellow and blue columns show the dose of

that a significant portion of this difference has its roots in the specific attributes of classic clinical studies, such as the selection of specific patients who are able to complete the study, higher frequency of visits, sufficient test strips to determine blood glucose, and customized titration diaries to support titration-to-target approach in randomized controlled trials. Most of these treatment elements in normal clinical practice cannot be systematically applied due to the time constraints of medical personnel.

A study with a design similar that of our BALI study which was conducted in Taiwan showed that an even lower portion of patients $(13.8 \%)$ achieved their target HbA1c values after 24 weeks of treatment. However, it must be noted that the mean baseline Hb1Ac level in the Taiwan study was higher $(87 \pm 18.8 \mathrm{mmol} / \mathrm{mol}$; DCCT $10.1 \pm 1.9 \%)$ than that in our study [21]. insulin administered by the patient during the period prior to each visit, and the gray bars show the dose recommended by the physician for the subsequent period of study

One of the main issues we focused on in our study was the method of titration in basal insulin therapy used by the participating physicians. Here, we found a few areas where improvement would, in our opinion, increase the effectiveness of this treatment. The first is the method of determining the initial dose of insulin. Our results show that physicians generally estimate the dose and do not use a weight-based calculation method. The average initial daily dose of basal insulin was approximately $0.13 \mathrm{U} / \mathrm{kg} /$ day in our study, which is close to the lower limit of the dosage recommended by care standards [22]. We can infer from this that doctors generally look at the patient as an individual, but not as an individual having a specific weight.

The second area where we see potential for improvement is the titration rate. In our study, 


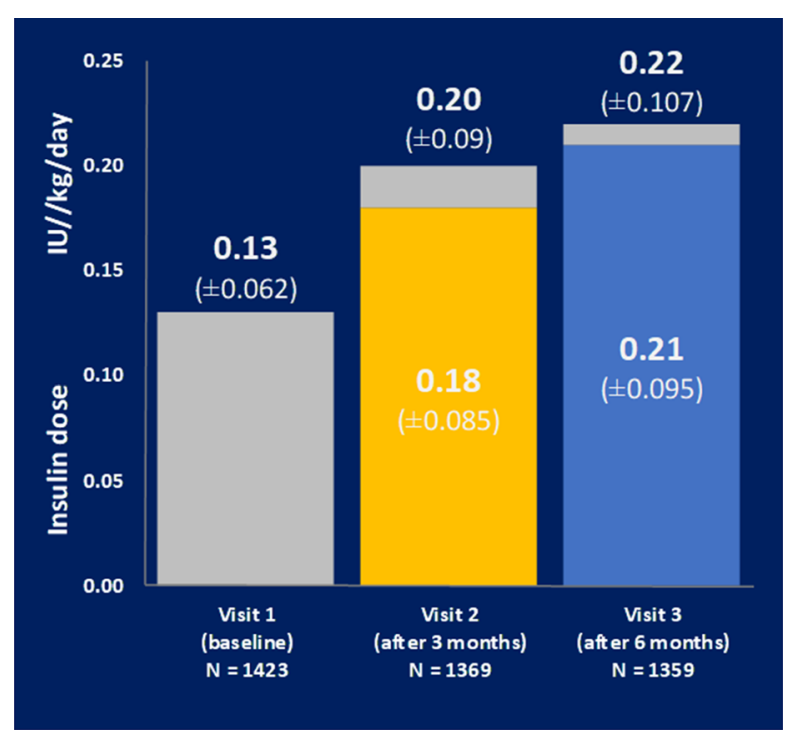

Fig. 2 The average dose of basal insulin per day as recommended by a physician for the subsequent period of study and the dosage titrated by the patient during the period prior to the visit (in $\mathrm{U} / \mathrm{kg} / \mathrm{day}$ ). The yellow and blue columns show the dose of insulin administered by the patient in the period prior to each visit, and the gray bars show the dose recommended by the physician for the subsequent period of study

after 6 months of treatment, the dosage was only slightly higher than the dosage recommended at the initiation of treatment. As only minor dose increases were recommended by physicians at the visits and only slightly higher ones were made by patients in between the visits, we recommend that more stress should be put on regular dose titration, including dose titration by patients. It is known that well-educated patients following a rational titration algorithm can achieve better glycemic control (HbA1c target) that titration based on periodic physician advice [23]. In the above-mentioned Taiwanese study, mean values per kilogram body weight and per day were not stated [21].

The third area for improvement that our analysis revealed was that the recommended increase in insulin dose was on average the same for patients who did not achieve improved HbA1c values after 3 months of treatment as for those who did achieve any improvement. This finding suggests that the patient's current HbA1c value was not always reflected in the

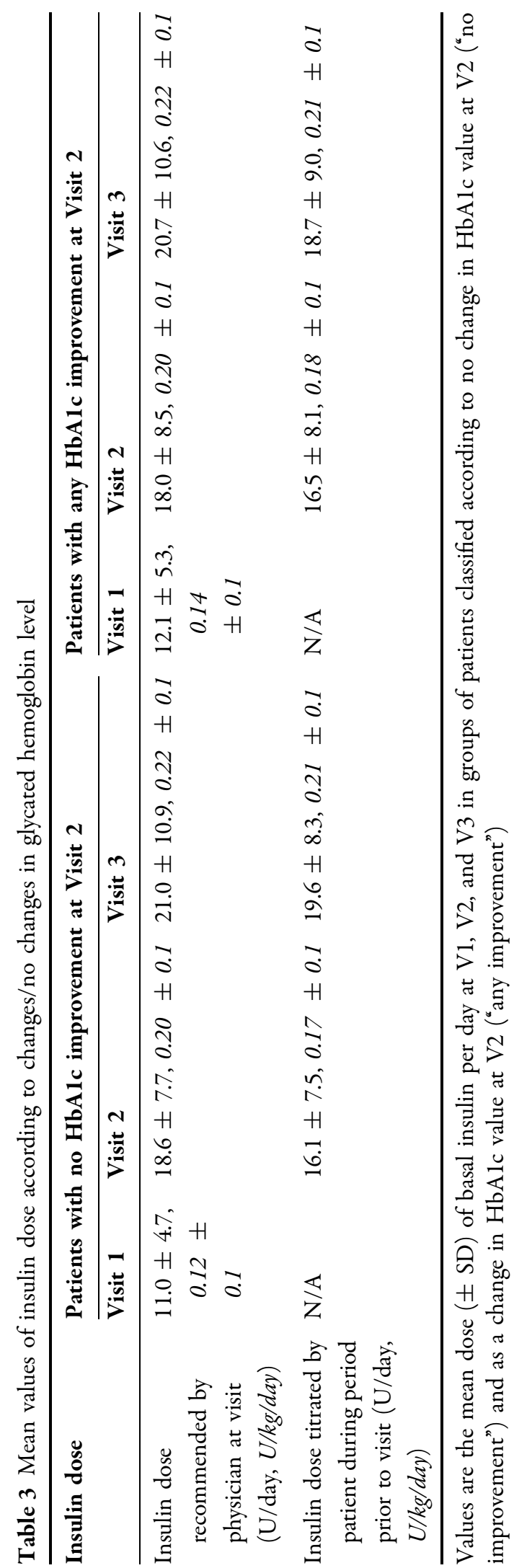


Table 4 Proportion of patients with occurrence of hypoglycemia during the study

\begin{tabular}{lllll}
\hline Period & $\begin{array}{l}\text { Number of } \\
\text { patients }\end{array}$ & $\begin{array}{l}\text { Patient with any reported } \\
\text { hypoglycemic event }\end{array}$ & $\begin{array}{l}\text { Patients with } \\
\text { severe } \\
\text { hypoglycemia }\end{array}$ & $\begin{array}{l}\text { Patients with } \\
\text { documented } \\
\text { hypoglycemia }\end{array}$ \\
\hline $\begin{array}{l}\text { From baseline to } 3 \text { months of } \\
\text { basal insulin therapy }\end{array}$ & 1402 & $88(6.3 \%)$ & - & $58(4.1 \%)$ \\
$\begin{array}{c}\text { From } 3 \text { months to } 6 \text { months } \\
\text { of basal insulin therapy }\end{array}$ & 1389 & $121(8.7 \%)$ & $1(0.1 \%)$ & $88(6.3 \%)$ \\
\begin{tabular}{l} 
During the study \\
\hline
\end{tabular} & 1410 & $173(12.3 \%)$ & $1(0.1 \%)$ & $130(9.2 \%)$ \\
\hline
\end{tabular}

Values are reported as the number of patients with or without the percentage in parenthesis

titration of the insulin dose, possibly due to, for example, changes in lifestyle or the addition of other antidiabetic medication which was not captured in this study.

The rate of overall hypoglycemia, including severe hypoglycemia, in our study was lower than that reported in other studies $[17,18,20]$, leading us to conclude that the therapy applied was safe in terms of glycemic control. A very similar although higher rate (11.8\%) was found in the Taiwanese study [21]. We also observed a small average increase in body weight (+ $0.4 \mathrm{~kg}$ ), but this small increase was of no clinical significance, and subgroup analyses did not reveal any consistent relationship between change in body weight and number of OADs or severity of diabetes based on HbA1c level.

Basal insulin titration is based on co-operation between the treating doctor and the patient and is influenced by a variety of factors, including concerns about hypoglycemia, the character and intellect of the patient, and the style of doctor-patient communication $[13,24,25]$. However, the results of our study suggest that physicians could be more tenacious in recommending baseline basal dosage and its titration.

A limitation to the study is that we do not know many patient details, including whether any of the physicians established an alternative HbA1c target due to their awareness of cardiovascular complications, nor do we know the reasons why the initial insulin dosages were lower than those recommended and why dosage titration was not more radical. Other limitations are that we did not examine patients' adherence to insulin therapy and the patterns of glucose self-monitoring.

However, we believe that the study produced several insights that could contribute to the increased effectiveness of baseline insulin titration.

\section{CONCLUSION}

The addition of basal insulin to insulin-naïve patients with T2DM currently on OAD treatment resulted in improved metabolic control after 6 months of treatment. The therapy was safe in terms of the frequency of hypoglycemia. However, most patients did not achieve their set HbA1c target, likely due to inadequate titration of basal insulin. Therefore, effective titration should be a subject of ongoing education.

\section{ACKNOWLEDGEMENTS}

We thank the study participants.

Funding. This study and associated article processing charges were funded by Sanofi, Czech Republic. The role of the sponsor was to appoint an independent research company and carry out the study (ADDS s.r.o.). All authors had full access to all of the data in this study and take complete responsibility for the integrity of the data and accuracy of the data analysis. 
Editorial Assistance. Special thanks to Nicholas Roy Arthofer for language editing.

Authorship. All named authors meet the International Committee of Medical Journal Editors (ICMJE) criteria for authorship for this article, take responsibility for the integrity of the work as a whole, and have given their approval for this version to be published.

Authorship Contributions. Jan Brož initiated the study and contributed to the study design, data analysis, and interpretation, as well as the drafting, review, and editing of the manuscript, and in doing so led all of the efforts. Denisa Janíčková Ždárská contributed to the study design and analysis and interpretation of the data, as well as to the drafting, review, and editing of the manuscript. Radka Štépánová contributed to the data analysis, drafting of the manuscript, and the review and editing of the manuscript. Milan Kvapil is a guarantor of this work and, as such, had full access to all the data in the study and takes responsibility for the integrity of the data and the accuracy of the data analysis.

Disclosures. Jan Brož has received payment for being an adviser to and a speaker for SanofiAventis s.r.o. and Eli Lilly s.r.o. Denisa Janíčková Ždárská discloses the receipt of financial support for the research, authorship, being a speaker, and being an educator for SanofiAventis, AstraZeneca, Eli Lilly, Novo Nordisk, Merc Sharp and Dohme, and Johnson \& Johnson. Radka Štěpánová works as a statistician for CRO Aprova s.r.o. which wes contracted by Sanofi-Aventis s.r.o. for the statistical analysis of this study. The authors report no other conflicts of interest in this work. Milan Kvapil has nothing to disclose.

Compliance with Ethics Guidelines. This study was conducted in accordance with the Declaration of Helsinki (2004) and the International Conference on Harmonization (ICH) Guidelines for Good Clinical Practice (1996). The study design was approved by the countryspecific regulatory authorities and ethical committees. All participants of the study provided signed informed consent.

Data Availability. The data sets during and/ or analyzed during the current study are available from the corresponding author on reasonable request.

Open Access. This article is distributed under the terms of the Creative Commons Attribution-NonCommercial 4.0 International License (http://creativecommons.org/licenses/ by-nc/4.0/), which permits any noncommercial use, distribution, and reproduction in any medium, provided you give appropriate credit to the original author(s) and the source, provide a link to the Creative Commons license, and indicate if changes were made.

\section{REFERENCES}

1. Selvin E, Parrinello CHM, Daya N, Bergenstal RM. Trends in insulin use and diabetes control in the U.S.: 1988-1994 and 1999-2012. Diabetes Care. 2016;39(3):e33-5. https://doi.org/10.2337/dc152229.

2. Pablos-Velasco P, Parhofer KG, Bradley C, et al. Current level of glycaemic control and its associated factors in patients with type 2 diabetes across Europe: data from the PANORAMA study. Clin Endocrinol. 2014;80:47-56.

3. Brož J, Janíčková Žd'árská D, Urbanová J, et al. Current level of glycemic control and clinical inertia in subjects using insulin for the treatment of type 1 and type 2 diabetes in the Czech Republic and the Slovak Republic: results of a multinational, multicenter, observational survey (DIAINFORM). Diabetes Ther. 2018;9:1897-1906. https://doi.org/ 10.1007/s13300-018-0485-2.

4. Stratton IM, Adler AI, Neil HA, et al. Association of glycaemia with macrovascular and microvascular complications of type 2 diabetes (UKPDS 35): prospective observational study. BMJ. 2000;321: 405-12.

5. Nathan DM, for the DCCT/EDIC Research Group. The Diabetes Control and Complications Trial/ Epidemiology of Diabetes Interventions and Complications Study at 30 years: Overview. Diabetes Care. 2014; 37:9-16. 
6. American Diabetes Association. Standards of medical care in diabetes-2017. Diabetes Care. 2017;40:S1-135.

7. Khunti K, Nikolajsen A, Thorsted BL, Andersen M, Davies MJ, Paul SK. Clinical inertia with regard to intensifying therapy in people with type 2 diabetes treated with basal insulin. Diabetes Obes Metab. 2016;18:401-9.

8. Calvert MJ, McManus RJ, Freemantle N. Management of type 2 diabetes with multiple oral hypoglycaemic agents or insulin in primary care: retrospective cohort study. $\mathrm{Br} \mathrm{J}$ Gen Pract. 2007;57:455-60.

9. Nichols GA, Koo YH, Shah SN. Delay of insulin addition to oral combination therapy despite inadequate glycemic control: delay of insulin therapy. J Gen Intern Med. 2007;22:453-8.

10. Nathan DM, Buse JB, Davidson MB, et al. Medical management of hyperglycemia in type 2 diabetes: a consensus algorithm for the initiation and adjustment of therapy: a consensus statement of the American Diabetes Association and the European Association for the Study of Diabetes. Diabetes Care. 2009;32:193-203.

11. Strange P. Treat-to-target insulin titration algorithms when initiating long or intermediate acting insulin in type 2 diabetes. J Diabetes Sci Technol. 2007; 1:540-8.

12. Ross SA, Tildesley HD, Ashkenas J. Barriers to effective insulin treatment: the persistence of poor glycemic control in type 2 diabetes. Curr Med Res Opin. 2011;27[Suppl 3]:13-20.

13. Berard L, Bonnemaire $\mathrm{M}$, Mical M, Edelman S. Insights into optimal basal insulin titration in type 2 diabetes: results of a quantitative survey. Diabetes Obes Metab. 2018;20:301-8. https://doi.org/10. 1111/dom.13064.

14. Workgroup on Hypoglycemia, American Diabetes Association. Defining and reporting hypoglycemia in diabetes: a report from the American Diabetes Association Workgroup on Hypoglycemia. Diabetes Care. 2005;28(5):1245-9.

15. Riddle MC, Vlajnic A, Zhou R, Rosenstock J. Baseline HbA1c predicts attainment of $7.0 \% \mathrm{HbA} 1 \mathrm{c}$ target with structured titration of insulin glargine in type 2 diabetes: a patient-level analysis of 12 studies. Diabetes Obes Metab. 2013;15:819-25. https://doi.org/10.1111/dom.12096.

16. Seaquist ER, Anderson J, Childs B, et al. Hypoglycemia and diabetes: a report of a workgroup of the American Diabetes Association and the Endocrine Society. Diabetes Care. 2013;36:1384-95.
17. Davies M, Lavalle-González F, Storms F, Gomis R, AT.LANTUS Study Group. Initiation of insulin glargine therapy in type 2 diabetes subjects suboptimally controlled on oral antidiabetic agents: results from the AT.LANTUS trial. Diabetes Obes Metab. 2008;10(5):387-99. https://doi.org/10.1111/ j.1463-1326.2008.00873.x.

18. Meneghini L, Kesavadev J, Demissie M, Nazeri A, Hollander P. Once-daily initiation of basal insulin as add-on to metformin: a 26-week, randomized, treat-to-target trial comparing insulin detemir with insulin glargine in patients with type 2 diabetes. Diabetes Obes Metab. 2013;15(8):729-36.

19. Riebenfeld D, Spirk D, Mathis A, et al. Treatment intensification with insulin glargine in patients with inadequately controlled type 2 diabetes improves glycaemic control with a high treatment satisfaction and no weight gain. Swiss Med Wkly. 2015;145(5):w14114.

20. Mauricio D, Meneghini L, Seufert J, et al. Glycaemic control and hypoglycaemia burden in patients with type 2 diabetes initiating basal insulin in Europe and the USA. Diabetes Obes Metab. 2017;19(8): 1155-64. https://doi.org/10.1111/dom.12927.

21. Chien MN, Chen YL, Hung YJ, et al. Glycemic control and adherence to basal insulin therapy in Taiwanese patients with type 2 diabetes mellitus. J Diabetes Investig. 2016;7(6):881-8. https://doi. org/10.1111/jdi.12532.

22. Garber AJ, Abrahamson MJ, Barzilay JI, et al. Consensus statement by the American association of clinical endocrinologists and American college of endocrinology on the comprehensive type 2 diabetes management algorithm-2018 executive summary. Endocr Pract. 2018;24:91-120.

23. Davies M, Lavalle-González F, Storms F, Gomis R. Initiation of insulin glargine therapy in type 2 diabetes subjects suboptimally controlled on oral antidiabetic agents: results from the AT.LANTUS trial. Diabetes Obes Metab. 2008;10(5):387-99. https://doi.org/10.1111/j.1463-1326.2008.00873.x.

24. Davies MJ, Gagliardino JJ, Gray LJ, Khunti K, Mohan V, Hughes R. Real-world factors affecting adherence to insulin therapy in patients with Type 1 or Type 2 diabetes mellitus: a systematic review. Diabet Med. 2013;30(5):512-24. https://doi.org/10. 1111/dme.12128.

25. Khunti K, Davies MJ, Kalra S. Self-titration of insulin in the management of people with type 2 diabetes: a practical solution to improve management in primary care. Diabetes Obes Metab. 2013;15(8): 690-700. https://doi.org/10.1111/dom.12053. 